\title{
Old Story, New Parlance: A Transcultural Analysis of The Liveaction Movie Mulan
}

\author{
Kaicheng $\mathrm{Lu}^{1, \mathrm{a}, *, \dagger}$, Yuquan $\mathrm{Liu}^{2, \mathrm{~b}, *, \dagger}$ \\ ${ }^{1}$ Sun Yat-sen University, Guangdong, China \\ ${ }^{2}$ China Academy of Art, Hangzhou, China \\ ${ }^{*}$ Corresponding author.Email: ${ }^{a}$ lukch@mail2.sysu.edu.cn, ${ }^{b} 15157705137 @ 139 . c o m$ \\ ${ }^{\dagger}$ These authors contributed equally.
}

\begin{abstract}
Recently Disney have rolled out the film Mulan which arouses a wide range of discussion. This research tries to find out how Disney film adapts a Chinese story in the Northern Wei period into an international film and why it is possible. Considering the deepening of the globalization and the development of modern media, to illuminate a movie targeting at global audience from a transcultural perspective is of great significance. It combines transcultural, multimodal and literature analysis. Through a transcultural lens, this paper fully refers to current research on transculturality and does both textual and image analysis to reveal the adaptation techniques of this film. It compares the Chinese version of Mulan with the film mainly from two aspects, namely, character and theme. It finally demonstrates that in spite of misinterpretation, the film Mulan is a transcultural explorative product. Through transcultural hybridization, it creates a third space in which different cultures interact with each other. This finding gives us a possibility to review the cultural products in a global context and from a transcultural perspective.
\end{abstract}

Keywords: Mulan, transculturality, globalization, adaptation, hybridization, third space.

\section{INTRODUCTION}

"Culture becomes a process of multinational assemblage, a flexible articulation of parts, a montage of features, that any citizen in any country of whatever religion or ideology can read and use" [1]. With the proceeding of globalization and mediatization, communication today has been increasingly characterized by transculturality [2], among which cultural products play an essential role. As the representative figure of globally available media products, Hollywood films have been in the growth of blockbusters with transcultural communicative features since the past few decades. Mulan released by Disney which is expected to make great progress only received a relatively lower grossing at last. Some websites also show that the reputation of Mulan also tends to go down [3]. Undoubtedly live-action Mulan has provoked controversial discussions of its representation of cultural symbols and its association with cultural hybridity.
There have been many studies illuminating this film from the perspective of cultural conflicts, but this paper hopes to explore new directions with a kind of "Copernicus spirit" beyond a late poltemic effort to "save this effort" [4], so as to fill in some loopholes of the practice of transcultural theory and provide implications for cross-cultural product production. Accordingly, this article aims at bringing the film Mulan into a more concise examination, seeking out the interaction and hybridity of different cultural aspects presented in the film, thus a new way to understand Mulan under the sight of transcultural theory.

Existing studies mainly analyze the movie from an intercultural perspective, criticizing its cultural misinterpretation and orientalist myth [5], arguing that the unbalanced media power founded by socio-economic inequality forms the production of Mulan under a western-centralist narrative [6]. On the contrary, a roundtable forum of Chinese scholars in the field of communication examined the film Mulan as a comparably potential case of transcultural 
communication [7]. Although the film contains symbolic cultural representations regulated by the Hollywood business model, its narrative of gender equality breaks the boundaries between cultures and shows its possibility to generate a third space [8]. In this sense, though Mulan is not a successful transcultural product, it indeed indicates the possibilities of transformation of communication from interculturality to transculturality. This research uses transcultural, multimodal literature analysis and the method of historical sociology. There is an interdisciplinary perspective in the use of literature, which guarantees the discussion of culture in this essay to be based on some reliable studies, such as American Social and Cultural Perspectives [9], The Formation of the Empire of the Sui, Tang Dynasty [10], and some historical material like Florentine histories [11]. Moreover, this study adopts a transcultural view which is based on Transucultrual Communication [12] and a wide range of treatises. Transculture means in the exchange and dialogue of two or more cultures, cultures undergo transformation and heteromorphosis [13].

As a result, this research finds that the film Mulan is produced through the acculturation of several specific cultures. The hybridization and third space created in the process prove further that Mulan is a meaningful transcultural attempt.

\section{A TRANSCULTURAL ADAPTATION OF A CHINESE STORY INTO A DISNEY FILM}

This chapter intends to explore the adaptation techniques of the film, based on different Chinese texts about the story of Mulan, and examine the cultural factors represented by this adaptation, namely to clarify how Mulan, a traditional Chinese cultural product, is internalized into a global film.

\subsection{Individualism in the character of Mulan}

In general, although Mulan in the film shares some personalities with Mulan in the poetry, she is different from the one in Chinese story. These differences are attributed to culture.

"Your job is to bring honor to our family", Mulan's father tells her in the film Mulan. As a result, Mulan indeed brings her family honor. She practices chi and becomes a great warrior. In the movie, Mulan is a gifted girl, born with strong chi, and she also has the qualities of courage and perseverance, which enable her to successfully use her ability to defeat the opponents in the war and save the country by her own efforts. This may be different from the traditional understandings of Mulan. In the Ballad of Mulan, there is no description about Mulan's family background, neither her gifts. Through the plots of the story, it could be known that Mulan is probably just an ordinary girl. She can succeed to "Rushing to northern frontier thousands of miles away"
( “万里赴戎机” ) and does well in a 12-year-war, which reflects that she does have extraordinary courage and strength, but what is more significant is that the heroine image behind Mulan is different. In the poem Mulan is a normal soldier fighting with other people. However, in the film Mulan becomes a wizardly woman who defeats the Rouran khan alone, which magnifies Mulan's personal role. It is quite a sense of personal heroism [14].

Such a paradigm of personal heroism can be easily found in many American films. Well-known super heroes all have their superpower which enable them to save the world by themselves. These kinds of heroes are the symbols of individualism in American culture. Some scholars pointed out that Americans are individualoriented, while Chinese people are group-oriented [15][16]. This distinction is highly dependent on some historical reasons. Some research argues that the individualism in the national character of Americans is influenced by the Puritanism of the Protestant settlement and their Mayflower Convention [17]. There are also no lack of theorists who thought that such individualism develops in the Westward Movement of the United States, through which the United States was able to develop into what it is today. In this campaign the connotation includes freedom and independence in life [18][19]. In the live-action film, Mulan is an embodiment of the individualist spirit. She decides her own way to bring honor to her family at liberty, saves the country by causing an avalanche, and defeats the Rouran leader on herself.

\subsection{The re-discussion of the gender topic and the filial piety in the theme}

The female consciousness and the idea of gender equality carried by Mulan deserve people's attention.

Mulan is not only a hero, but also a female heroine born in feudal China, which is her unique aspect. What this article means by uniqueness is that her story is a betrayal of the traditional Confucian thoughts which require women to be gentle and virtuous. In this sense, Mulan, as a heroic woman and a talented solider, cannot be tolerated. Many scholars have noted that the emergence of such a unique heroine image has a lot to do with the nomadic people who came into China at that time [20]. Medieval China has always been an era of heroines, which is related to the nomads or Inner Asian peoples. After the Inner Asian nations established their kaiserdom in the north of China, a new culture appeared and the old empire and order completely collapsed [21]. With both contradiction and integration, the values and cultures of Hu people (胡) and Han Chinese merged. The Inner Asian warlike ideology allows both men and women to go to war and use their powerful force, so Mulan's image should have overlapped with the nomadic horsewoman's. The story continued to progress. In the Ming dynasty, when the city economy began to boom, 
many plots about Mulan had somewhat judgmental and eccentric colour. In the drama Ci Mulan (雌木兰 Female Mulan), Mulan said, "I dressed up and pretended to be a man, killing the enemy and catching their king, which is easy for me.” (我杀贼把王擒, 是女将男换, 这功劳 得将来不费星儿汗). At this time, Mulan story was a response to the literati's worship of talented women and a group of women who expected to go out of their homes [22].

The filmmakers made good use of the feminist factor in Mulan's story, which makes us view the film as a rediscussion of the gender topic of the previous ones. They developed the gender meaning in the film into a more modern shape. For example, Mulan can easily climb up a hill with two buckets of water while other male soldiers fail to do that. Through this clip, the producer wanted to convey the ideas that Mulan is just as capable of completing difficult tasks as a man, and that her strength and perseverance are no less than a man's. In the final battle of the film, Mulan defeats the leader of barbarians by his broadsword which is considered as a weapon used by men. It is undoubtedly that the need of telling a story with the concepts of gender equality and the liberation of women drives the film makers to adapt this legend into a film with more feminism odour.

At the same time, the film Mulan also partly transforms the concept of filial piety (xiao 孝). In the film, Mulan, who is unable to bring honor to her family through marriage, chooses to join the army for her father in her own way. This belief runs through Mulan. The culture of filial piety is indeed one of the most important kernels in Mulan's story, but the filial piety in the film is obvious in the other directions compared with the filial piety in the ancient time. First, the story of Mulan happened during the Northern Wei Dynasty. Previous studies fully proved that the local society at that time was controlled by the nobles, which means that the local system of small family unity in the movie should not have existed at that period [23]. Besides, some scenes can also be seen in which Mulan and Mulan's father try to communicate with their ancestors in the front of the memorial tablets in a small room. Nevertheless, the traditions of setting consecrating tablets of ancestors and worshiping them in a hall in the folk appeared at least after the Jiajing period of the Ming Dynasty [24]. These two points reveal that the filial piety presented by the moviemaker is not from the story of Mulan itself or so called "the history of China", but the internalized understanding of the concept of filial piety. In a way, in the process of adaptation, they misrepresented the tradition of ancestors worship.

Some of the family factors in the film come from the ancient form of the western family. Xiao or the filial piety in the film adds the idea of honor into family value which can be dated back to the medieval Europe and the family system of ancient Roman. First the emblem of Hua's family in the film is probably from the history of clan emblem of middle age Europe [25]. Second, the method to put filial piety into practice in the movie is to become a warrior or to get married, but it is a mixture of imagination and the family notions in medieval Europe where chivalry let knights gain honor through wars and wealth [26][27]. However, according to the Confucianism, filial piety has three connotations: being filial to parents, maintaining worship to ancestors, and serving the country with loyalty [28]. It is a totally different story. Third, the father in the film appears to be a tyrant in the family and asks every family member to obey his order unconditionally which becomes the reason that Mulan has to leave home without saying any words to her parents. Some researches show us that in the Roman families fathers were always like autarchies [29]. So these plots become the evidences that the film combines the notions of family of ancient China, medieval Europe and ancient Roman.

\section{HYBRIDIZATION AND THIRD SPACE: A MEANINGFUL ATTEMPT ON THE WAY TO TRANSCULTURALITY}

After discussing the adaptation and its reasons, this chapter will analyze the hybridization and the third space created by Mulan.

\subsection{Hybridization in the film Mulan: under the view of feminism}

In the background of mediatization and globalization, the boundaries between cultures are not fixed, stable, and clear [30]. Originally used to describe a chemical reaction, hybridization is borrowed by cultural studies to describe the phenomenon of generating a new culture with the interaction of different cultural elements. The gender structure in the film Mulan, is a typical instance of hybridization. In the film, what Mulan faces is the systematic discrimination against women, whether in or outside the family. Most women in the feudal society accept the roles put on them. It is their duty to bring honor to their family through marriage. They are supposed to be gentle, decent, and well-behaved. Therefore, Mulan feels extremely frustrated when she messes up in front of the matchmaker. Not only women, represented by Mulan's mother and the matchmaker but also men support such a gender structure. Although Mulan's father gives her freedom to some extent, he is still one of the strongest defenders of this system. He is opposed to Mulan's decisions of joining the army. However, driven by the situation, she chooses to against her family's will, being a warrior to bring honor to her family. Moreover, she is banished from the army by the general when she exposes her female role even though she has saved the whole army. However, the story does not stop here, where patriarchy dominates the society as in the history. 
Mulan is born with a talent, called "chi" which enables her to challenge the system. With chi, she saves the country and rewins respect from both female and male characters. In a way, the gender structure seems shakeable and feminism is born as the first chapter shows. Female is allowed to fight in the war and even live with male soldiers.

One of the reasons for Disney to do such kinds of adaptations is its audiences. What the film Mulan faces is the global market. And Disney is skilled at repackaging an ethnic story in a way that global audiences are all familiar with, such as good prevailing over evil and young romance [31]. In that case, cultural hybridization is meant to happen. For global audiences in the modern world, feminism is a conversant element which can hardly be distinguished by national countries or geography. To signify gender equality, Disney has to weaken the authenticity of the original story and sacrifice some historical facts.

However, such a hybridization is mechanical, which means that the feminism embodied by Mulan is in a way a paradox. Mulan is the only role with such an ability. And this ability is a gift in the family rather than her selfconsciousness and self-awareness. The witch with the same ability and the other ordinary women are incapable to recognize gender discrimination in their society, not to mention fighting against it. On the one hand, Disney strengthens the stereotypes about ancient China, which received fierce criticism from Chinese audiences. On the other hand, it gives female agency to break these stereotypes, but such agency is limited and exclusive. Therefore, such a hybrid feminism is not convincing. It reflects the contradictions in the process of hybridization. While cultural thickening happens, cultural thinning is unavoidable. Transculturality is not to romanticize cultural interaction but to show the unfixed boundary between culture.

Nowadays feminism is a popular topic in Disney films. However, in other films, without hybridization of different cultures, the gender structures in these films make more sense. For example, in Frozen, both Elsa and Anna are fully aware of their female consciousness and have the ability to rescue themselves and other in the end [32].

\subsection{Transcultural third space brought by the hybridization}

Nevertheless, hybridization also brings possibilities, opening up transcultural third space which constructs "the discursive conditions of enunciation that ensures the meaning and symbols of culture have no primordial unity or fixity" [33]. Cultures meet each other and alter themselves like a new material created in the melting pot. As mentioned in chapter 1, the film Mulan combines the notions of western cultures with Chinese ones, such as the idea of honor. As a result, the film Mulan presents audiences with a timeless and spaceless story that cannot be put into any historical contexts. Meanwhile the story happens in a third space which doesn't belong to any culture.

The story of Mulan happened during the Northern Wei Dynasty. Neither the small family unity in Mulan nor the traditions of worshiping ancestors would appear at that time. Moreover, the form of the house only emerged after the Tang Dynasty [34]. Also the power named chi and the appearance of phoenix are not likely to happen at that time.

One of the western concepts that is emphasized repeatedly in the movie is honor. Through chapter 1, it could be known that the concept of honor in the film is more similar to the one in medieval Europe rather than ancient China. However, it does not conflict with other Chinese philosophy mentioned in the film, namely bravery, loyalty, integrity, and devotion to the family. By practicing these principles, Mulan brings honor to her family and the whole country. It is in this third space that possibilities happen.

The birth of such a transcultural third space "requires a process of dialectic discourse and reflective interaction through which ideas, values, and meaning clash and are negotiated and regenerated" [35]. It can be even said that the whole film as a transcultural product is a third place itself. In which misunderstandings and even conflicts happen with transformation and possibilities. The film breaks the bounds among the cultures which can be clearly separated by languages, distances and the ethics. Therefore, a transcultural adaptation is an efficient method to enhance the influences of a culture. It is beneficial for a better understanding towards discrepant civilizations. From this perspective, the film Mulan is actually a meaningful attempt though not that successful.

\section{CONCLUSION}

In conclusion, the 2020 Disney live-action animated film Mulan is a transcultural attempt. Adapted from a well-known Chinese folk tale, it presents a new story with different characters and themes. Mulan is aware of her responsibility to bring honor to her family and embodies the idea of feminism. However, cultural hybridization results in both misrepresentation and possibilities. The feminism in the film is not consistent. It is more like a tool for Mulan rather than a challenge to the whole gender structure. Nevertheless, it creates also a third space where different cultures interact, negotiate, and integrate. It blurs the cultural boundaries.

Adopting a new theoretical system to reinterpret transcultural communication is demanded under the changing conditions of the international landscape and media technology. This article tries to explore a new way to understand cultural products both in the past and 
present. A transcultural perspective is useful for people to abandon cultural prejudices. It emphasized that.

\section{REFERENCES}

[1] Nestor Garcia canclini. Consumers and Citizens: Globalization and Multicultural Conflicts. Minnesota: Univ of Minnesota Press, 2001, pp.3847.

[2] Kraidy, Marwan M. Communication and Power in the Global ERA. 2012, New York: Routledge press.

[3] Zhou Shiyu. Mulan "Unaccustomed to Water and Soil"--Viewing the live-action version of "Mulan" from the perspective of cross-media secondary coding. Yiyuan, 2020, pp.41-44.

[4] Benedict Anderson. Imagined community. 2011, Shanghai: Shanghai renmin chubanshe.

[5] Jiao Sue, Zhao Yanghua. Xifang shijiao xia de dongfanggushi-cong donghuadianying <Hua Mulan>dao zhenrendianying <Hua Mulan> [The Eastern Story from the Western Perspective--From the animated film "Mulan" to the live-action film "Mulan"], xinyang shifan xueyuan xuebao (zhexue shehui kexue ban), 2021, pp.107-111.

[6] Wang Cheng, Ju Fei. <Hua Mulan>zhishang: haolaiwu de dongfangmisi [The Death of "Mulan": Hollywood's Oriental Myth] Dianying wenxue, 2021, pp.94-97.

[7] Liu ying, zhang yu qiang. Zhuanwenhua chuanbo: zhonghuawenhua "zoucgyqy" de shengji xinkeneng-jiyu <Gongfu xiongmao $><H u a$ Mulan> [Cultural Dissemination: New Possibilities for Upgrading Chinese Culture "Going Global"-Discussion based on cases such as "Kung Fu Panda" and "Mulan"], Duiwai chuanbo, 2021, pp.52-56.

[8] Cao Xingrui. Nuxing zhuyi shiyu xia de shenfenrentong-yi dishini zhenrenban dianying $<$ Hua Mulan>weili [Identity in the Perspective of Feminism--Taking Disney's live-action movie "Mulan" as an example], Shiting, 2021, pp.82-84.

[9] DuanmuYiwan. Meiguo shehui wenhua toushi [A Perspective of American Society and Culture], 1999, Nanjing: Nanjing daxue chubanshe

[10] Tanigawa Michio. Suitangdiguo xingcheng shilun [On the History of the Formation of Sui and Tang Empires], 2011, Shanghai : shanghai guji chubanshe.
[11] Machiavelli. Fuoluolunsa shi [Florentine histories], 2011, Changchun: jilin chuban jituan youxian zeren gongsi.

[12] Andreas Hepp, Transcultural Communication, John Wiley and Sons Inc, 2015.

[13] Shi Anbing, Sheng Yang. Cong kua dao zhaun xin quanqiuhua shidai chuabo yanjiu de lilunzaizao yu lujingchonggou [From "Span" to "Transfer": Theoretical Reconstruction and Path Reconstruction of Communication Studies in the New Globalization Era]. Dangdai Chuanbo, 2020, pp.18-24.

[14] Li Wenya. Qianxi Hua Mulan renwu xingxiang de lishi yanbian [Analysis on the Historical Evolution of the Characters of Hua Mulan]. Beifang Wenxue, 2006, pp.32-34

[15] Zhao Xiaolan. Yimin yu meilijian minzu xingge [Immigration and American National Character]. Tianjin shifan daxue xuebao(shehui kexue ban), 2002, pp.40-43

[16] DuanmuYiwan. Meiguo shehui wenhua toushi [A Perspective of American Society and Culture], Nanjing: Nanjing daxue chubanshe, 1999, pp.53.

[17] Xu Fen. Cong <Mayflower Convention> dao xijin yundong-yingxiang meiguo minzu xingge xingcheng de ruogan shijian fenxi [From the "Mayflower Convention" to the Westward Movement: An Analysis of Several Events Affecting the Formation of American National Character] Henan shehui kexue, 2009, pp.154-156.

[18] DuanmuYiwan. Meiguo shehui wenhua toushi [A Perspective of American Society and Culture] Nanjing: Nanjing daxue chubanshe, 1999, pp. 53.

[19] S.E. Morison. Meilijian gongheguo de chengzhang [The Growth of the American Republic], Tianjin: Tianjin renmin chubanshe, 1980, pp.336

[20] Nie Xinrong, Xie Zhenyuan. Chenshixue shiyexia de huamulna yunixingjiefang de weidu [Hua Mulan from the Hermeneutics Perspective and the Dimension of Women's Liberation], Chongqin: Chongqin daxue xuebao(shehui kexue ban), 2002 , pp.56-62.

[21] Tanigawa Michio. Suitangdiguo xingcheng shilun [On the History of the Formation of Sui and Tang Empires], 2011, Shanghai: shanghai guji chubanshe.

[22] Nie Xinrong, Xie Zhenyuan. Chenshixue shiyexia de huamulna yunixingjiefang de weidu [Hua Mulan from the Hermeneutics Perspective and the Dimension of Women's Liberation], Chongqin: Chongqin daxue xuebao(shehui kexue ban), 2002, pp.56-62. 
[23] Tanigawa Michio. Suitangdiguo xingcheng shilun [On the History of the Formation of Sui and Tang Empires], Shanghai: shanghai guji chubanshe, 2011, pp.110-111.

[24] Changjianhua. Mingdai zongzu ciji zulizhi jiqiyanbian [The Etiquette System of Ancestor Worship in Clan Temples and Temples in Ming Dynasty and Its Evolution]. Nankai xuebao, 2001, pp.60-67.

[25] Li songjing. Lun xiou zhongshiji ishizhuang jiecengbiaozhi de wenhuayiyi [On the Cultural Significance of the Marks of the Medieval Knights' Costumes], 2009, Tianjin: Tianjin shifan daxue.

[26] Ni Shiguan. Qishizhidu yu xiou zhongshiji zhanzheng [Chivalry and Medieval Wars in Western Europe], Beijing: zhongguo shehuikexue, pp.160185+207-208.

[27] Machiavelli. Fuoluolunsa shi [Florentine histories], Changchun: jilin chuban jituan youxian zeren gongsi. When Machiavelli extols Cosimo de' Medici, he firstly mentions his great bounty and his grandiose mansions, which directly contact wealth and noble personality(although Machiavelli opposes wealth inequality and the political power it offers). This proved that in mediaeval Europe wealth bought people honor, 2011, pp353-354.

[28] Chen Xiaofang. Xiaode de qiyuan jiqi yu zongfa, zhengzhi de guanxi [The origin of filial piety and its relationship with clan system and politics], Chengdu: xinan minzu daxue xuebao(zhexue shehui kexue ban), 2000, pp.118-125.

[29] Xu xiaowang. Gudai zhongguo, luoma jiazu zhidu ji xifang lijie dongfang de wuqu [Ancient Chinese and Roman family systems and the misunderstanding of the East in the West], Guangzhou: xueshu yanjiu, 2000, pp.81-87.

[30] Andreas Hepp,Transcultural Communication,John Wiley and Sons Inc, 2015, pp.10.

[31] Georgette Wang and Emilie Yueh-yu Yeh, Globalization and hybridization in cultural products, international journal of cultural studies, Vol.8, No.2(2005), pp.178.

[32] Lin Danya. Xingbie shijiao xia de dishini gaibian Mulan zhi kaobian [Review of Mulan adapted by Disney under the view of gender]. Tianjin:Nankai xuebao, 2019, Print.

[33] Andreas Hepp,Transcultural Communication,John Wiley and Sons Inc, 2015, pp.20.

[34] Xie Li. Fujian tulou xingcheng fazhan de lishi dili huanjing yanjiu [Research about development of
Fujian earthbuilding in fields of history and geography]. Changsha:Hunan shehu kexue, 2011, Print.

[35] Georgette Wang and Emilie Yueh-yu Yeh, Globalization and hybridization in cultural products,international journal of cultural studies, Vol.8, No.2(2005), pp.188. 